\title{
VUOSIKIRJAN 2017 KIRJOITTAJAT
}

Marjukka Colliander, FM, tohtorikoulutettava, Tampereen yliopisto, Marjukka.Colliander@staff.uta.fi

Sirkku Kotilainen, FT, professori, Viestintätieteiden tiedekunta, Tampereen yliopisto, Sirkku.kotilainen@uta.fi

Anu Laukkanen, FT, tutkijatohtori, Turun yliopisto,anu.laukkanen@utu.fi

Aleksi Lohtaja, YTM, tohtorikoulutettava, Yhteiskuntatieteiden ja filosofian laitos, Jyväskylän yliopisto, aleksi.o.lohtaja@student. jyu.fi

Satu Olkkonen, TeT, tutkijatohtori, Nuoret Estradille -hanke (2015-2017), Tampereen yliopisto, satu.m.olkkonen@gmail.com

Katri Talaskivi, FM, YTM, tohtorikoulutettava, Jyväskylän yliopisto, katri.a.talaskivi@jyu.fi

Anne Teikari, FM, tutkimussihteeri, Kulttuuripolitiikan tutkimuskeskus Cupore, anne.teikari@cupore.fi

Taneli Viitahuhta, FM, tohtorikoulutettava, Yhteiskuntatieteiden ja filosofian laitos, Jyväskylän yliopisto, taneli.viitahuhta@gmail. com 